\title{
Jovellanos en Puerto de Vega, una vida y un destino
}

\author{
Servando Fernández Méndez
}

«Amigos de la Historia» (Puerto de Vega)

\section{Resumen}

La presente investigación razona que el bergantín Volante en que Jovellanos huía de las tropas francesas no se refugió en el puerto de Vega casualmente, sino debido a la existencia en dicha localidad de parientes directos de la primera mujer de Pedro Manuel Valdés-Llanos, Josefina Méndez de Vigo.

\section{Palabras clave}

Jovellanos. Puerto Vega. Pedro Manuel Valdés-Llanos.

Concluía el día 27 de noviembre de 1811 — el día 28, según atestiguan otros reputados biógrafos - cuando la muerte sorprendió a Jovellanos, prematuramente viejo, enfermo y cansado, en una acogedora casona de la parroquia de Santa Marina de Veiga, concejo de Navia. Era Gaspar Melchor de Jovellanos —o Melchor Gaspar Baltasar María, si atendemos a la textualidad del acta de nacimiento, perdida en el fragor de la Guerra Civil y recuperada por digitalización de una copia del original que firmaba el párroco Fabián Tuñón- el décimo hijo de don Francisco Gregorio de Jovellanos y doña Francisca Apolinaria Ramírez de Jove, y nieto materno, por lo tanto, de doña Francisca María Fernández de Miranda y Ponce de León Trelles, hija de los marqueses de Valdecarzana, la cual estaba directamente emparentada CES.XVIII, núm. 15 (2005), págs. 45-63. 
con un linaje establecido en Puerto de Vega, concejo de Navia, al socaire de la pujanza económica portuaria y de la que varios vástagos, durante buena parte del siglo XVIII, habían venido monopolizado ininterrumpidamente el influyente cargo de comandantes- administradores de rentas de la Aduana, la que más cotizaba a la Real Hacienda durante aquel periodo de bonanza económica ${ }^{1}$.

¿Tuvo algo que ver esta circunstancia familiar, hasta ahora poco atendida por la historiografía, con la arribada al puerto de Vega del bergantín Volante, o tal decisión fue tomada por su inseparable amigo Pedro Manuel Valdés-Llanos y Menéndez — su entrañable confidente Petris de los escritos intimistas-, el cual tenía parientes directos en la entonces aldea naviega? En el actual estado de la cuestión, intuimos que ésta fue la causa última de la decisión de buscar refugio en el pequeño puerto de Vega, descartando el más próximo, cómodo y seguro puerto de Luarca; como elemento probatorio, aducimos el acta de defunción del propio Valdés Llanos, la cual antecede a la de Jovellanos en el Libro V de Defunciones (folio 65, vuelta) del archivo parroquial de Santa Marina de Puerto de Vega, que dice textualmente:

Vega. Dn. Pedro Llanos, viudo. En veinte y seis de noviembre de mil ochocientos once, yo, el infraescripto cura propio de Santa Marina del Puerto de Vega, di sepultura en esta mi iglesia al cadáver de Dn. Pedro Llanos, viudo, vecino de Gijón, estuvo casado en primeras con Josefa Méndez de Vigo, de cuyo matrimonio no dejó familia alguna. Murió el día anterior auxiliado de los Sacramentos de Penitencia, Viático y no la Extremaunción, no hubo lugar, no testó [...].

Este linaje de los Méndez de Vigo era oriundo del lugar homónimo, sito en la parroquia de Santa Marina de Puerto de Vega. Empadronados como hidalgos notorios desde tiempo inmemorial, habían centrado su actividad económica, secularmente, en el comercio al por mayor, accediendo repetidas veces, aunque con diferentes representantes de la influyente familia, a la presidencia o diputación del poderoso Gremio de Marinería y Comercio de Vega, el que más contribuía a la Real Hacienda durante varias décadas del siglo XVIII².

1 Sobre este linaje de los Miranda Ponce de León asentados como comandantes del resguardo de Rentas de la Aduana del puerto de Veiga, como se llamaba entonces la actual villa, se han aportado interesantes estudios por parte de: J.P. FERRERía, Evolución civil y organización agraria del Principado de Asturias, Rosario (Argentina), 1914, págs. 199-204; L. NAVIA Osorio, Datos para una historia del concejo de Navia, Oviedo, 1979; J. MartínEZ, «El siglo XVIII: el municipio y las gentes», BIDEA n. ${ }^{\circ} 52$ (1964), págs. 309-311, «El siglo XIX: final de un letargo», BIDEA, n. 56 (1965) y Una panorámica de la villa y concejo a través de los tiempos, Navia, 1973, págs. 14-23; y S. Fernández Méndez, «Astilleros Armón», Oviedo, Ediciones Nobel, 2002, págs. 30-31.

2 Se puede ampliar la información en: C. Fernández González, Puerto de Vega hacia mediados del siglo XX, Puerto de Vega, 2003, anexo IV, págs. 11-15; también en S. Fernández Méndez, Una iglesia para un 


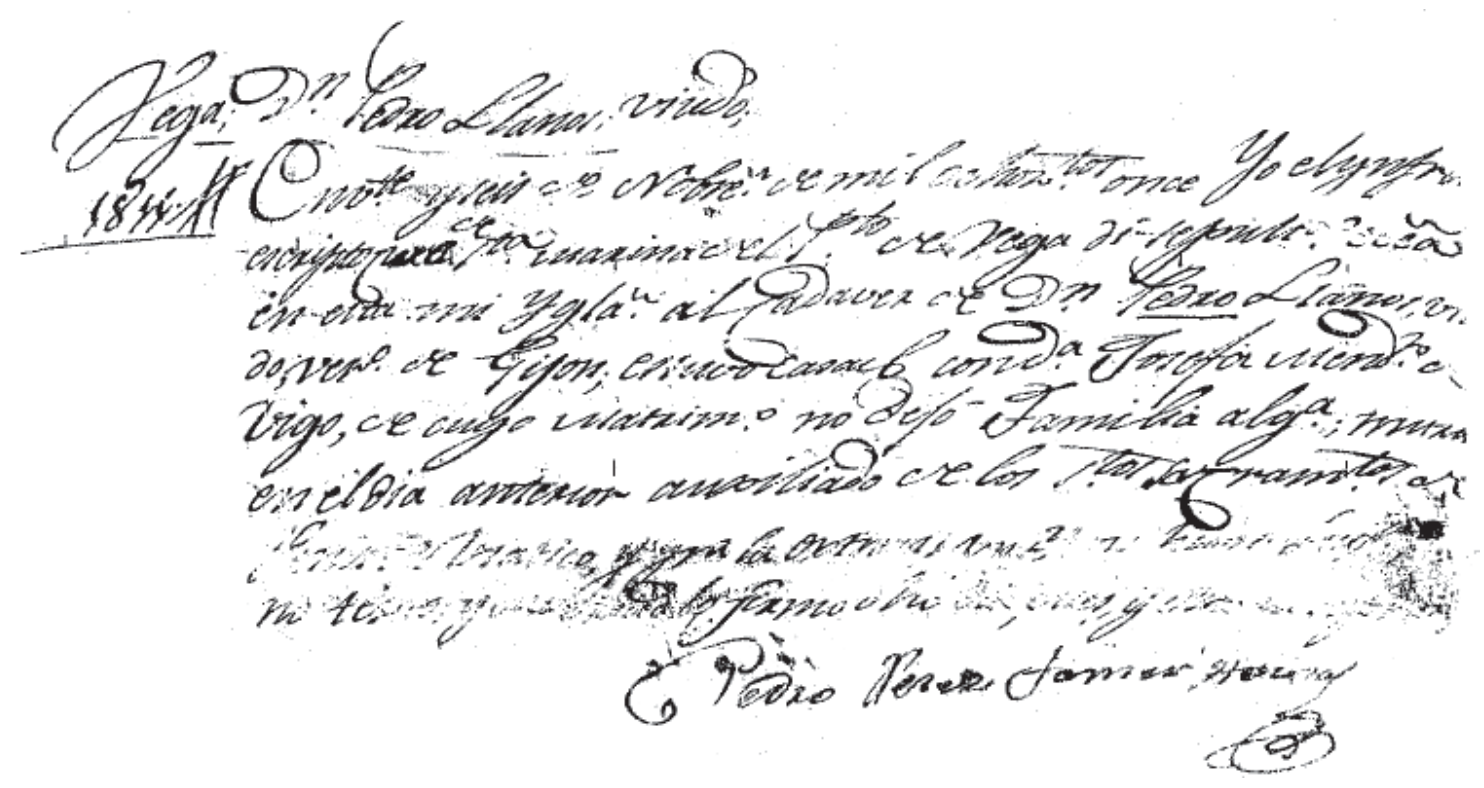

Un minucioso estudio genealógico sobre esta familia nos ha permitido concluir que la esposa de Pedro Valdés Llanos se llamó en vida Josefa Dolores Méndez de Vigo y Fernández del Cueto; había nacido en Oviedo y fue bautizada en la parroquia de San Tirso el Real el día 18 de noviembre de 1756. El matrimonio entre ambos se celebró el día 7 de noviembre de 1774, pero la mencionada Josefa era hija de Gregorio Méndez de Vigo y Flórez Villamil, nacido en Veiga el 26 de septiembre de 1708 y de María Fernández del Cueto Lanza Trelles, de idéntica procedencia. Este encumbrado personaje fue diputado del poderoso Gremio de Marinería y Comercio, rico propietario de bienes inmobiliarios y comisario de obras de la iglesia parroquial de Santa Marina y del inconcluso hospicio franciscano, siendo donante del retablo de su santo patronímico ubicado en el crucero de dicha iglesia, además de la campana principal, advocada a Santa Bárbara ${ }^{3}$.

Pocos días antes de su óbito, concretamente el día 6 de noviembre, el prócer gijonés, a quien acompañaba un nutrido séquito de amigos, todos ellos de relevante consideración social —Ceán menciona unas setenta personas ${ }^{4}$ habían zarpado con urgencia del puerto de su amada ciudad natal, en un ber-

pueblo, Puerto de Vega, Portfolio de Nuestra Señora de la Atalaya, 1994. Pueden hallarse noticias generales sobre este periodo en las obras de J. MarTínEZ antes reseñadas y en «Navia en el siglo XVIII según el Catastro de Ensenada», BIDEA, n. ${ }^{\text {os }}$ 84-85, págs. 73-76.

3 Más datos acerca de este personaje se pueden encontrar en S. Fernández Méndez, Una iglesia para un pueblo (1994), Marcas que dejan huella (1996) y El Hospicio de Vega (1992), en Portfolios de fiestas de Nuestra Señora de la Atalaya (Puerto de Vega).

4 J.A. Ceán Bermúdez, Memorias para la vida del Excmo. Sr. D. Gaspar Melchor de Jovellanos y notas analíticas de su obra, Madrid, 1814. 
gantín vizcaíno, denominado Volante, a causa de la inquietud nacida de una nueva incursión de las tropas francesas en la comarca. Jovellanos, rehén de su propio e infortunado destino, hubo de hacer acopio de sus alicaídas fuerzas para abandonar una vez más su añorada tierra y embarcarse en un largo y trágico periplo costero que, tras una breve escala en el puerto de Ribadeo — donde les aguardaba una fragata británica, presta para zarpar-, habría de conducirles a la amistosa y liberal Londres o quizás, con mejores argumentos, a la Isla de León, sita en la costa de la constitucionalista Cádiz y, a la sazón, sede provisional de la Junta.

Desde el mismo momento de la partida, todas las circunstancias hacían presagiar un trágico e inevitable epílogo, ya que tras franquear con bastante incertidumbre la peligrosa bocana del puerto gijonés, «bordeando para zafarse de la concha», se produjo un inesperado y desafortunado incidente con un buque inglés, el Garnesey, cuando éste levaba anclas y ponía rumbo a la homónima isla británica. La chispa fue provocada por el capitán de este carguero, el cual intentaba recuperar el efectivo de una multa de sesenta mil reales, dictada por la Aduana gijonesa y que había satisfecho a regañadientes, tras ser probada la comisión de un delito de contrabando de unos cuatrocientos quintales de bacalao. La tripulación se enfrentó verbalmente al cónsul inglés, el cual iba como pasajero a bordo del Volante y hasta se disparó un cañonazo que pasó rozando el costado del bergantín.

Este primer incidente se superó sin mayores contratiempos, pero cuando el frágil navío se adentró en el mar abierto, un impetuoso viento del noroeste le impedía navegar, frenando pertinazmente su pesado desplazamiento; luego, tras su estela, se originó una imponente galerna del Cantábrico, que convirtió en infausto viaje en una dramática epopeya. Por fin, ocho días después de la apresurada partida, habiendo aprovechado algunos periodos de calma del inquieto océano y, tras descartar sorprendentemente la lógica arribada al protegido y seguro puerto de Luarca, el capitán puso rumbo a Veiga, una cercana aldea poblada por experimentados marinos y pobres campesinos, donde los abatidos fugitivos fueron socorridos con desinteresada hospitalidad por estos humildes vecinos hasta que el generoso y solícito amigo Antonio Trelles Osorio puso a disposición de tan exhausta comitiva su casa y sus bienes. Esta prodigalidad, no exenta de tópicos, fue objeto del elogio apasionado de la poetisa local Conchita Díaz:

¡Puerto de Vega! ¡Edén hospitalario oculto de la peña en una brecha, que cual vigía atento y solitario, 
con un fin puramente humanitario,

la nave que peligra siempre acecha! ${ }^{5}$

La modesta pluma de la maestra local Manuela Fernández inmortalizó hace casi ochenta años un pasaje que no menciona ninguno de los biógrafos habituales del polígrafo gijonés, argumentando que Jovellanos, tras haberse recuperado de las penurias del infausto viaje y encontrándose momentáneamente pletórico entre tanta gente amigable, exclamó mientras ascendía las escaleras del puerto por las que accedió al pueblo y que aún hoy desafían el tiempo, unidas inexorablemente a las almenas dieciochescas, una frase lacónica, de enfático y sincero agradecimiento: «Vega, tú serás la vega». Quizás por la turbada mente del noble prócer, aquejado de febril debilidad y desazón, pasó la idea de que su huida permanente había alcanzado el remanso en aquel pequeño puerto de refugio olvidado de todos. Una vez más se equivocaba, pues en aquel instante fugaz de renacida euforia se había comenzado a escribir la página final de su infausta existencia, a la par que el glorioso prólogo de su inmortalidad.

Uno de sus últimos biógrafos, en estricta cronología, Agustín Guzmán Sancho, ha aportado interesantes argumentos documentales sobre algunos aspectos desconocidos de este postrer viaje de Jovellanos, demostrando cómo el capitán Juan de Sertucha, vecino de Plencia (Vizcaya), acompañado por sus tripulantes Juan Bautista Domingo Muniategui, Antonio de Basterra y Juan Bautista de Gaviri, levantó dos «protestas de mar», para evitar responsabilidades sobre el barco y su flete tras las muchas penalidades que habían soportado. En la primera de ellas da cuenta de cómo «a dos leguas de mar les alcanzó un tiempo malo del este o noreste que les hizo navegar a la mar hasta el día 14 a la boca noche, desde el cinco que se habían hecho a la mar, aunque no se separaron de Gijón por no poder coge el rumbo y no poder regresar», todo ello a causa de la presencia de los enemigos ${ }^{6}$.

Puntualiza también el capitán en su declaración que el barco llevaba un cargamento de cajas de cigarros, papeles y otros efectos de la Real Hacienda, sin duda por orden taxativa de Valdés Llanos, a la sazón administrador en Gijón de dicha institución, el cual desearía poner a buen recaudo una parte significativa del patrimonio de la misma.

5 Este fragmento forma parte del poema titulado «A Puerto de Vega», escrito por la poeta local, aunque nacida en las orillas del Darro granadino, Conchita Díaz. Fue publicado en el semanario El Porvenir Asturiano en el año 1907.

6 A. Guzmán Sancho, «Nuevas postrimerías de Jovellanos», Boletín Jovellanista, n. ${ }^{\circ}$ IV (2003), págs. $51-52$. 
En suma, entre las dos y tres de la tarde del jueves 14 de noviembre, según acredita uno de los más reputados biógrafos jovellanistas, el químico castropolense José Ramón Luanco, el Volante arribó a puerto, iniciándose para Jovellanos el último y penoso peregrinaje que halló triste conclusión en el momento de su óbito. Empapado por la invernal atmósfera de agua y salitre, mortalmente enfebrecido, Jovellanos y los demás viajeros entraron en contacto con la tierra firme en las escalerillas de las Almenas; pocos minutos después, el prócer accedió con sus acompañantes a la confortable casa de su viejo amigo Antonio Trelles, ubicada en la denominada entonces calle del Café y rebautizada posteriormente en homenaje al insigne morador, atravesando las míseras callejas que, nacidas en el corazón del puerto, concluían en la denominada calle Real y en La Plaza, arterias vitales de la aldea, quizá cantada demasiado enfáticamente por Campoamor — «Del mar junto a la orilla está Vega, / lugar que, aunque pequeño para ser una villa, / casi es un Londres para ser aldea»-, aunque también rigurosamente desmerecida por el biógrafo jovellanista Juan Agustín Ceán Bermúdez, quien la calificó de «aldea miserable», según refiere el mismo José Ramón de Luanco en 1881.

Lo acompañaban —al decir del escritor naviego Fermín Campoamor ${ }^{7}$ varios amigos y/o correligionarios, hallándose entre ellos José López Lamagna, cirujano gijonés de cierto mérito, que había sido médico de la Armada y que en los días venideros adquiriría un triste e inmerecido protagonismo, aprovechado por Julio Somoza para tildarle de «hombre de pocos alcances», ahondando en la apreciación negativa de José Ramón Luanco, si bien Lamagna fue en realidad un honrado profesional que ocupó la plaza de cirujano titular gijonés desde 1804 hasta su muerte en el año 1817, salvo en el intervalo 1813-15. También fueron testigos del infausto viaje su inseparable amigo Pedro Manuel Valdés-Llanos, Pedro Zulaybar y el fiel criado coañés Domingo García de la Fuente, a quien había conocido en Madrid en el domicilio del embajador en Rusia, Miguel Gálvez, en el año 1792, incorporándolo desde entonces a su servicio9.

7 F. Campoamor, «Jovellanos», Río Navia (agosto de 1932).

8 A. Guzmán Sancho, «El cirujano Lamagna», Boletín Jovellanista, n. ${ }^{\circ}$ V, 2004, pág. 234.

9 Domingo García de la Fuente, el honrado servidor coañés de Jovellanos, se convirtió desde entonces en su compañero de penurias, demostrando una lealtad acendrada, pues llegó a cederle sus ahorros de doce mil reales para que pudiera vivir con la decencia concerniente a su noble apellido. Había nacido en Coaña el 7 de marzo de 1752 y fue quien acompañó a nuestro hombre en las interminables y tristes horas del destierro mallorquín. Protegió la integridad de su equipaje en el bergantín Volante, suceso que estuvo a punto de costarle la vida el día 15 de noviembre de 1811, cuando el barco fue destruido por la mar embravecida. El mismo día 29 de noviembre de 1811, dada la eventual trascendencia de la documentación que portaba Jovellanos destinada a disponer de ella en su supuesto exilio en Inglaterra, se hizo inventario urgente de sus bienes, que el fiel criado hubo de conducir ese mismo día a casa de su hermano Pedro, tras el entierro, una vez que el juez por el estado noble, José Benito Campoamor y la Vega, había tomado diligencias urgentes. Posteriormente, 
Quizás ya en aquellos duros momentos, el demudado espíritu y el febril y débil cuerpo habían equilibrado su decadencia formal, acompasando sus últimos latidos vitales. La noche del día 15 y hasta altas horas de la madrugada del día siguiente, la galerna se fue recrudeciendo, provocando grandes estragos en el otrora seguro puerto de refugio. El bergantín Volante, atracado previsiblemente en el lugar conocido como La Poza, rompió sus amarras, que estaban sujetas a tres bolardos y fue arrastrado hasta la bocana, mientras la siguiente ola lo introducía, de nuevo, violentamente en el puerto, partiéndose en dos el bauprés y yendo a estrellarse contra un petón del puerto junto a la fuente de Caborno, provocando unas vías de agua que las dos bombas se mostraron incapaces de $\operatorname{achicar}^{10}$.

Ese día, en arriesgada y muy loable operación de rescate, el fiel criado Domingo García de la Fuente, quien aún permanecía a bordo para salvaguardar los enseres de su señor, consiguió, con ayuda de los vecinos, asirse con fuerza a un murallón — sin duda, el de las Almenas, levantado sobre los restos de un bastión bajomedieval—, logrando recuperar el equipaje, el cual, a la muerte del prócer, decidió trasladar a casa de su hermano Pedro, residente en Coaña, para su custodia; otros, como el biógrafo Ceán, contradicen que este traslado tuviese lugar el mismo día de la pérdida del barco, dadas las dramáticas condiciones en que se había producido tal arribada ${ }^{11}$.

Se ha especulado bastante acerca de que una leve mejoría de la galerna, acaecida el día 16, llegó a alumbrar en los viajeros la esperanza de reanudar el viaje hacia el puerto de Ribadeo, escala necesaria para abordar la fragata inglesa que les había de conducir a la liberada Cádiz o a la liberal Inglaterra; nos parece sencillamente imposible conciliar esa noticia con la anterior, pues

fue depositario de la herencia de su amo hasta que se posesionó de ella el legítimo heredero universal del malogrado Jovellanos. El probo varón fue nombrado años más tarde regidor decano de su municipio natal y escribano de número, aunque dejó pronto el cargo por un asunto poco claro que lo llevó a ser procesado, según refiere Canella; por fin, murió el 31 de julio de 1823, soltero, si bien estuvo casado sólo unos días con una coañesa, dejando herederos a sus hermanos residentes en su municipio natal. Véase F. Canella SECades, Domingo García de la Fuente, Oviedo, 1902 (reed. 2001), págs. 118.

10 En el Libro de Actas de la Junta General del Principado, fechado en 1810, pero referido a tres años antes, se dice del puerto de refugio de Veiga: «Este puerto tiene barra y ésta hace canal entre dos arrecifes, uno a la parte del E. y otro a la contraria; el canal tiene de ocho a nueve brazas de agua, fondo sable. Se puede entrar a la bajamar con barcos de catorce pies marinos y dan fondo entre puntas a cuatro amarras en el paraje que llaman El Pozo, a esperar el flujo y entrar en la dársena, cuyo amarradero es seguro y abrigado en todo tiempo, con la circunstancia de quedar en seco a la mar baja... Vega ha sido puerto de bastante concurrencia de buques y de mucho comercio, pero hoy sólo se conservan dos bergantines que ejercitan el cabotaje y pertenecen a individuos de la propia villa. Hay algunas lanchas de pesca y un corto número de gente matriculada que no llega a cuarenta y hacen la pesca de mar enfuera, al bonito y merluza, usando la red volante para este último; todos los objetos que se presentan a la vista dentro de Vega manifiestan su estado de decadencia».

11 J.A. Cé́n Bermúdez, Memorias, págs. 120-121. 
no tenía sentido el mencionado traslado de enseres a Coaña si tenían pensado partir ese mismo día; además, era algo ilógico e innecesario, pues no estaban en casa enemiga y para el traslado hacía falta una buena recua de caballerías, nada fáciles de reunir en unas horas. El testimonio de Ceán tampoco aporta suficiente luz para zanjar la cuestión:

De repente a las dos de la mañana del mismo día 16 se levanta otra cruel tempestad al tiempo de llenar la marea, que rompiendo las amarras del buque, le arrastra al mar la resaca. Una oleada de creciente le precipita al puerto; pero otra resaca torna a llevarle al piélago, tronchando el palo de proa contra un peñasco. [...] Después de tres horas de haber bregado animosamente, otra ola más fuerte que las anteriores arroja el bergantín entre dos peñas, y aunque haciendo agua, sin desgracia de persona alguna, y sin pérdida de los equipajes, que se sacaron después sin lesión a tierra ${ }^{12}$.

El infausto, triste destino, ya estaba escrito, aunque algunos estudiosos de la talla del inolvidable erudito local Pedro Penzol o el mencionado José Ramón Luanco, se esfuerzan en recrear a un Jovellanos plenamente vital hasta casi su postrer suspiro, dando testimonio de que asistió a misa el día 17 y conversó largamente en el pórtico de la iglesia con los hermanos Santamarina, vástagos instruidos de una dadivosa familia que, con los Méndez de Vigo, habían sido los grandes hacedores del templo barroco, construido entre los años 1730 y $1749^{13}$.

Un posible aval de esta tesis se halla en la última carta que Jovellanos escribe o, más bien, dicta a un amanuense y luego firma. Estaba fechada y signada en Veiga el día 20 de noviembre e iba dirigida al general Abadía, aunque algunos biógrafos contemporáneos, entre los que se hallan Jesús Martínez y Agustín Guzmán, coinciden en afirmar que dos días antes ya estaba enfermo, afectado de una flegmasía pulmonar aguda o, siendo más precisos, de una neumonía lobar inferior izquierda, cuya veloz y dramática evolución acabó en pocos días con la fértil e infausta vida del noble pensador asturiano.

La carta dirigida al general Abadía y escrita cuando, muy posiblemente, Jovellanos era ya presa de la enfermedad y otra, con fecha posterior a su muerte, aunque supuestamente redactada unos días antes que la anterior, a bordo del

12 J.A. CeÁn Bermúdez, Memorias, pág. 121.

13 Los Pérez Santamarina fueron donantes del prodigioso retablo de la Virgen del Carmelo, una de las grandes joyas de la transición del barroco al rococó en Asturias, salida del mágico cincel de José Bernardo de la Meana, último maestro arquitecto de la catedral ovetense. Como en el caso de los Méndez de Vigo, ocuparon habitualmente el cargo de diputados del Gremio de Marinería y Comercio. 
Volante, fueron publicadas en el año 1973 por el doctor Jesús Martínez. La primera — y más difundida ${ }^{14}$ — decía así:

Mi muy estimado General y mi dueño: ¿Conque Asturias acaba destinada a una tercera esclavitud bajo la protección de V.M.? ¿Conque se esperó fuese inevitable y próxima esta nueva invasión para privarla de ella y arrojarla del sexto ejército? ¿Y que se la excluya de él cuando ningún nuevo motivo persuada esta dislocación? ¿No hubiera sido mejor abandonarla desde el principio a sí misma, dejarla a sus valientes soldados, el derecho a los socorros del gobierno y el goce exclusivo de lo que con tanto celo sacó de sí misma, que confiar su defensa a los que tan mala cuenta dieron de ella? ¡Desgraciada provincia condenada siempre a tan mala suerte por los mismos que debían salvarla! Romana (Pedro Caro Sureda, marqués de La Romana) la vendió infamemente en 1809. Arce (Antonio) la abandonó cobardemente en 1810. $\mathrm{Y}$ ahora se la deja perecer sin que nadie tienda una mano amiga en su socorro y se le roba la protección de V.M. que siempre libraba la esperanza de su libertad. Pero, ¿qué tan irrevocable será la sentencia de su emancipación que pierda del todo esta esperanza y no deje a V.M. ningún arbitrio de socorrernos? No lo puedo creer. No es posible que V.M. sea espectador tranquilo de nuestra ruina. La fuerza invasora es corta; la que se halla en esa frontera no es grande; la que está bajo la mano de V.M. puede atender todo y parece justo lo haga por lo menos entre tanto que se arregla esta intempestiva dislocación y se organiza el $7 .^{\circ}$ Ejército y su mando. Oiga, pues, V.M. los clamores de nuestra Junta y sea el libertador de esta provincia para cuya gloria parece haberle destinado el Cielo. Socórranos V.M. pues, si no por nuestro interés, por el de la provincia que manda. No espere nunca que perdida Asturias se conserve Galicia. No espere que los débiles esfuerzos de ese indolente basten a evitar su ruina y tema más bien que con su casi millón y medio de habitantes perezca si tuviese que defenderse solo por Oriente y Mediodía; y por ventura, ¿si se pierde el Norte se conservará el Reino de España? Infiera V.M., pues, que no es mi interés personal ni sólo el de mi país el que me mueve a dirigirle estos clamores; muéveme el interés de nuestra heroica y afligida nación. Por mi parte, he perdido cuanto tenía y lo que es más, perdida la dulce ilusión de hacer algún importante servicio a mi Patria voy a esconderme en la Isla y a esperar en algún rincón el término de una vida tan agitada, resignado si logro dejar mis huesos en un poco de tierra libre de España: ¡Ojalá que mis años me permitiesen dejarlos en el campo de batalla concurriendo a la venganza de tantos ultrajes como ha sufrido de sus bárbaros invasores! Perdone V.M., amigo mío, este desahogo de la opresión con que han puesto mi espíritu tan tristes ocurrencias, y seguro del constante aprecio y

14 J. Martínez Fernández, «La última carta de Jovellanos», BIDEA, n. 78 (1973), págs. 214-215. 
de la fina amistad que le profeso, créame que soy siempre su más seguro servidor y apasionado amigo Q.S.M.B.

Gaspar Melchor de Jovellanos

Sr. D. Francisco Abadía Vega y a Nre. 20 de 1811.

La autoría y oportunidad de esta primera carta nos parece fuera de duda, aun a sabiendas de que Jovellanos estaba ya postrado en cama, mortalmente enfermo, desde dos días antes, aunque perfectamente lúcido y animado vanamente en proseguir viaje a la Isla, término impreciso que algunos biógrafos quieren identificar con las islas Británicas, aunque parece más razonable que se refiera a la Isla de León, sede del Consejo Supremo de Regencia. Dado el febril estado de salud del gijonés, no se trata de una carta autógrafa, sino que fue dictada a un amanuense; en la detallada misiva, el prócer recrimina al general Abadía su pasividad ante la cuarta invasión francesa, al mando de Bonnet, pues si bien esta última fue menos cruenta y no superó el mes de duración, el VI. ${ }^{\circ}$ Ejército, dirigido por el socorrido general, se hallaba ajeno al peligro, entretenido en acciones bélicas de escasa importancia en la retaguardia leonesa. Igualmente, Jovellanos no desaprovecha la oportunidad para zaherir con inusitada dureza la nefasta actuación del general La Romana — que había fallecido el 3 de enero de ese mismo año- y sus sucesores, los cuales habían dejado a Asturias totalmente desguarnecida y a merced de su propio destino.

En cuanto a la segunda misiva, hallada en el mismo lote de documentos que la anterior y escrita de la misma mano de amanuense, presenta un serio problema de datación, aunque se quiera fijar su fecha en el día 10 de diciembre, pues Jovellanos había fallecido unos días antes. Jesús Martínez atribuyó esta circunstancia a un probable error del copista en su redacción o bien a que éste expresó la fecha de su posterior trascripción. Tampoco está claro a quién iba dirigida la carta, pues el texto conservado no lo indica, si bien el probable destinatario habría de ser el presidente del Consejo de Regencia, general Castaños, admirado héroe de Bailén. Y, más que una carta, hemos de interpretarla como un acta acusatoria sobre la errónea gestión de la seguridad del país asturiano por parte de los rectores militares y políticos de la región, poniendo especial énfasis en señalar la responsabilidad de los generales La Romana, Arce, Mahy y Losada, sin obviar una atinada propuesta de mejoras insoslayables, entre ellas la de la unificación del mando en la persona del general Pedro de la Bárcena, por lo que se puede considerar el testamento político, a título póstumo, del prócer gijonés. La carta dice lo siguiente:

Señor: No siempre, con vivo dolor mío y de todos los buenos españoles, he de clamar en vano a los que nos gobiernan por el facilísimo remedio de los males 
de mi desgraciada provincia Asturias, Hoy padece esta tierra, proscripta como las de Madián o Dumer, entregadas como ellas a la espada enemiga por nuestros negligentes gobiernos, padece, digo, la cuarta irrupción de las tropas del tirano Napoleón. Sufrió la primera irrupción hasta el río Navia, desde donde los nobles asturianos no permitieron que tales fieras pisasen más de cinco leguas de su suelo y las rechazaron animosamente por sí solos. Segunda irrupción hicieron los tigres franceses en Asturias porque con apariencias de toda deliberación se lo permitió el General Marqués de la Romana que, por la flojedad de la Junta Central que se decía gobernaba a España, se atrevió a venir de mano armada sobre la ciudad de Oviedo, a calumniar su Junta, destruirla, perturbar la provincia y abandonarla vergonzosamente sin presentar su cara al enemigo. Y esto fue sufrido del que se llamaba gobierno de España al que la Junta de Asturias se quejó de tanto desacato a su rey y a su provincia, y siempre en vano; y tan flaco gobierno lo fue hasta negarme tribunal en que demostrar yo que, como miembro de aquella Junta, fui calumniado de tan ruin General, cuya ineptitud al mando intenté probar. ¡Y a este general exigió V.M. una lápida sepulcral digna de Gonzalo de Córdoba! La tercera irrupción la padeció Asturias cuando mandada por el General don Antonio de Arce, la abandonó al enemigo vergonzosamente, de lo que en vano me quejé porque nuestros gobiernos parece que miraron estos males como leves, o como incorregibles, y por esta tercera irrupción gozaron a Asturias los enemigos casi año y medio; porque la primera regencia hizo la siniestra elección para sus reconquistadores de los generales Mahy (Nicolás) y Losada (Francisco Javier), de cuya ignorancia y flojedad hice a V.M. palpable demostración, pero también en vano, porque a pesar de ella honró V.M. al General Mahy con el mando de su ejército y confirmó al general Losada con el de esta desventurada provincia. Este inepto General, tan notoriamente incapaz de mando grave, permitió a los viles satélites del tirano que penetrasen en Asturias y la talasen a su salvo; y V.M. que oyó mis demostraciones de su insuficiencia, no admite jamás que las confirme, repitiendo sus ignorancias y negligencias. Si tantas fueron las de que me quejé, no espere V.M. que sean menos las que él repita, mientras que V.M. le autorice a ello conservándole en el mando, lo que con verdad digo es autorizarle a repetirlas, pues que son como forzosas en él por su crasa ignorancia y palpable flojedad. ¡Cuántas pruebas, Señor, presente a V.M. y cuán en vano! No crea V.M. ofendido su acatamiento porque un súbdito le avise una desacertada elección; gloria es, sí, de V.M. reconocerla por sí, ya por el aviso de buen español; y aún mayor gloria corregirla, pues que los Príncipes, aunque Dioses de la tierra, están expuestos al error. Y si V.M. no aprovecha los bien intencionados recuerdos de los celosos españoles como yo, que tantas veces supliqué a V.M. y a los demás gobiernos que corrigiesen sus desaciertos, exponiéndome a la venganza y a los desaires públicos que sufrí, ¿qué buen español parecerá ante V.M. a desahogar el 
ardor de su patriotismo gritando por el bien de sus compatricios? ¿Cuántas veces clamé a V.M. y a los anteriores gobiernos contra la probada ineptitud de este mal llamado General? ¿Cuántas contra la notoria inacción de la Audiencia de Asturias en desarmar aquella provincia, la primera para su gloria y mi voz levantada contra el tirano? ¿Y me oyó V.M.? ¿Y me oyeron los otros gobiernos? No, Señor; así pues, algunos españoles creen que el silencio de V.M. es una bondad suya para conmigo, que debiera ser tratado como calumniador de aquel vil tribunal, o como autor de desacato a V.M., que así muestra su grandeza en despreciarlo; más otros españoles, Señor, llaman constante mi celo en repetir pruebas de él, sin esperar más que su desprecio y una como pena de calumniador en el silencio de V.M. que con él da vilantez a aquel infame cuerpo a que más y más me veje en mi hacienda ya que no puede en mi honor, a que así, Señor, sea maltratado un celoso español. Séalo, pues, con admiración de los que también lo son; pero jamás por ello dejaré de repetir que el General Losada es crasamente ignorante y vergonzosamente flojo y así incapaz de defender una provincia; y también repetiré sin temor de los más graves males que la Audiencia de Asturias en notoriamente infiel a la Religión y a la Patria, lo que a V.M. debe constar, así por habérselo afirmado yo tantas veces, como por la pública voz y fama de toda la nación que admira el que a su pesar permita V.M. ser miembros suyos a dos de aquel vil cuerpo, de los que uno tiene la horrible especialidad de ser un regente interino, cuando cometió la felonía de desarmar a aquella noble provincia para agasajar al tirano con su esclavitud. ¿Ignora acaso V.M. que el Obispo de aquella desventurada tierra cometió igual traición cuando estuvo de su parte? Si la pública voz y fama no bastasen a V.M. para creerlo, séanle un más que superabundante proceso sus cuatro adjuntas pastorales que forman ante V.M. una muy solemne y probada acusación. ¿Puede ser feliz la desgraciada Asturias cuya autoridad militar está colocada en una persona notoriamente incapaz de ejercerla, la Contenciosa en un cuerpo que todos llaman infiel a la Religión y a la Patria, y la Eclesiástica en un indigno pastor que más bien es lobo rabioso? Lastímese, pues, V.M. de tan infeliz tierra siendo la cuna de la resistencia a la tiranía, pues fue la primera en levantar el grito y la espada; y del, como tantas veces pedí a V.M. por su Comandante General al glorioso D. Pedro de la Bárcena, bajo el cual los asturianos tantas veces combatieron a las tropas del tirano con satisfacción de vencer y lo lograron. Déle V.M. otro Tribunal Contencioso en que no se vea a todas horas la imagen de la traición, arrojando al mismo tiempo de sí como cómplices de ella, por ser miembros suyos e indignos de serlo de V.M., a D. José López del Pan y a D. Miguel de Zumalacárregui, que así satisfará el anhelo de toda la nación. Disponga también V.M. que sea otro el digno Obispo de Asturias ya que el de hoy ni es digno de llamarse español. Y mande V.M. formar de nuevo y déle otra Junta Provincial pues la que hoy la rige no es legítima, como que ella misma reconoció, según el 
adjunto testimonio de su Secretario, que muchos de sus electores no tenían las calidades prescritas por V.M. y aún faltan también a no pocos de sus elegidos. Yo, Señor, elevo a V.M. estos clamores poniendo por testigo al Señor de la verdad y de la justicia, de que estas me los dictan, con lo que espero sean bien oídas de V.M. A 10 de diciembre de $1811^{15}$.

Unos días después, en concreto el día 25 de noviembre, la muerte sorprendió a su inseparable amigo Pedro de Valdés Llanos, a quien Jovellanos habría prestado muy solícitos cuidados en el trance de su agonía, noticia biográfica que debe tomarse con absoluta cautela. Al día siguiente, el cadáver del inseparable amigo fue sepultado en el interior de la iglesia parroquial de Santa Marina, posiblemente en la tumba perpetua dotada desde 1732 por la familia de su fallecida esposa; curiosamente, el acta de su defunción precede en el asiento del libro parroquial al de su inseparable mentor.

La triste noticia hubo de significar — si llegó a ser conocedor del evento en plena lucha con la cruel enfermedad que también a él le azotaba- la definitiva rendición vital de Jovellanos. Su precaria salud se fue agravando por momentos y, aunque el otrora mencionado cirujano gijonés Lamagna estaba entre los que le habían acompañado en el dramático viaje a bordo del Volante, éste pronto se vio sobrepasado por la progresiva y mortal decadencia física del prócer, incapaz de responder al tratamiento elegido, fundamentado en el recurso a cantáridas y otros inocuos potingues. El progresivo empeoramiento de la salud del enfermo estimuló a alguien del entorno próximo — posiblemente su anfitrión Antonio Trelles- a recurrir a un cirujano naviego, José Angulo, el cual pronto comprendió la irreversibilidad de la enfermedad, dado el avanzado estado de agonía del paciente, pronosticando un inminente desenlace, fatídicamente confirmado por los hechos poco después.

En una carta remitida al biógrafo José Ramón Luanco por el mencionado doctor José Angulo en enero de 1851, éste critica con dureza la ineficacia del colega gijonés, que hoy se tiende a minimizar y disculpar, dada la absoluta carencia de medios para atajar la mortal enfermedad. En ella escribía el mencionado galeno:

Fue atacado el Sr. Jove Llanos de un frío general con dolor vivo y agudo en el costado izquierdo, dificultad de respirar, esputo sanguíneo y calentura violenta. El cirujano La Magna desconoció enteramente este estado patológico morboso de tanta gravedad, omitiendo el emplear oportunamente un método antiflogístico para

15 J. Martínez Fernández, «La última carta de Jovellanos», págs. 214-219. 
combatir con fruto la flegmasía de pulmón, cuyos síntomas se manifestaban evidentemente; pero por desgracia no ocurrió así. De esta manera pasaron los días y siguieron las cosas sin tomar otras providencias; hasta que pasado el primer septenario de su afección, llamaron al octavo día al facultativo Angulo; pero ya era demasiado tarde. Éste se cruzó de brazos, pues el Sr. Jove Llanos estaba atacado de un fuerte delirio y su razón trastornada, repitiendo a cada instante: «Mi sobrino... Junta Central... la Francia... Nación sin cabeza... Desdichado de mí» y otras incoherencias. Se encontraba en los últimos instantes de su existencia, y no pudo tampoco concluir su testamento, que había principiado; y después de recibir los auxilios de nuestra Sacrosanta Religión expiró tranquilamente, sin agonía, el día diez de su enfermedad, a las cuatro de la tarde.

¿Ocurrió el fatídico desenlace el día 28 de noviembre, como refleja el acta parroquial de defunción y defendió con ahínco y argumentos sólidos Jesús Martínez, o fue el día anterior, según infieren otros biógrafos, como Ceán y Luanco? Ciertamente, la fecha del 27 alcanzó mayor consenso en la historia, aunque la primera habría de ser incuestionable, si hacemos caso estricto al acta de defunción. La pertinaz defensa de la fecha del día 27 por su biógrafo más cercano, Ceán Bermúdez — quien, además de matizar que había recibido los santos sacramentos unas horas antes, puntualiza la hora de la defunción «entre nueve y diez de la noche, a los sesenta y seis años, diez meses y veintidós días de edad»—, unida a ciertos aspectos colaterales que parecen avalarla, mereció la confianza de otros estudiosos, como José Ramón de Luanco, quien infiere que la presencia de los cuarenta sacerdotes de las feligresías y de los dos vocales de la Junta General que llegaron desde Castropol no se podía sustanciar en veinticuatro horas:

Al funeral de cuerpo presente asistieron cuarenta sacerdotes de las feligresías inmediatas, que no se convocan en pocas horas, y que presidieron el duelo dos vocales de la Junta del Principado, refugiada con todas las autoridades legítimas en la villa de Castropol, distante seis leguas del Puerto de Vega; de suerte que el adjetivo anterior no deba entenderse el inmediato ${ }^{16}$.

Esta misma tesis es compartida por uno de los biógrafos jovellanistas contemporáneos, Agustín Guzmán Sancho, quien, aportando datos juiciosos y precisos, concluye que un funeral de tal magnitud no se hubiera podido preparar en veinticuatro horas; en defensa de su tesis, Sancho recupera el testimonio tardío

16 J.A. Ceán Bermúdez, Memorias, pág. 122. 


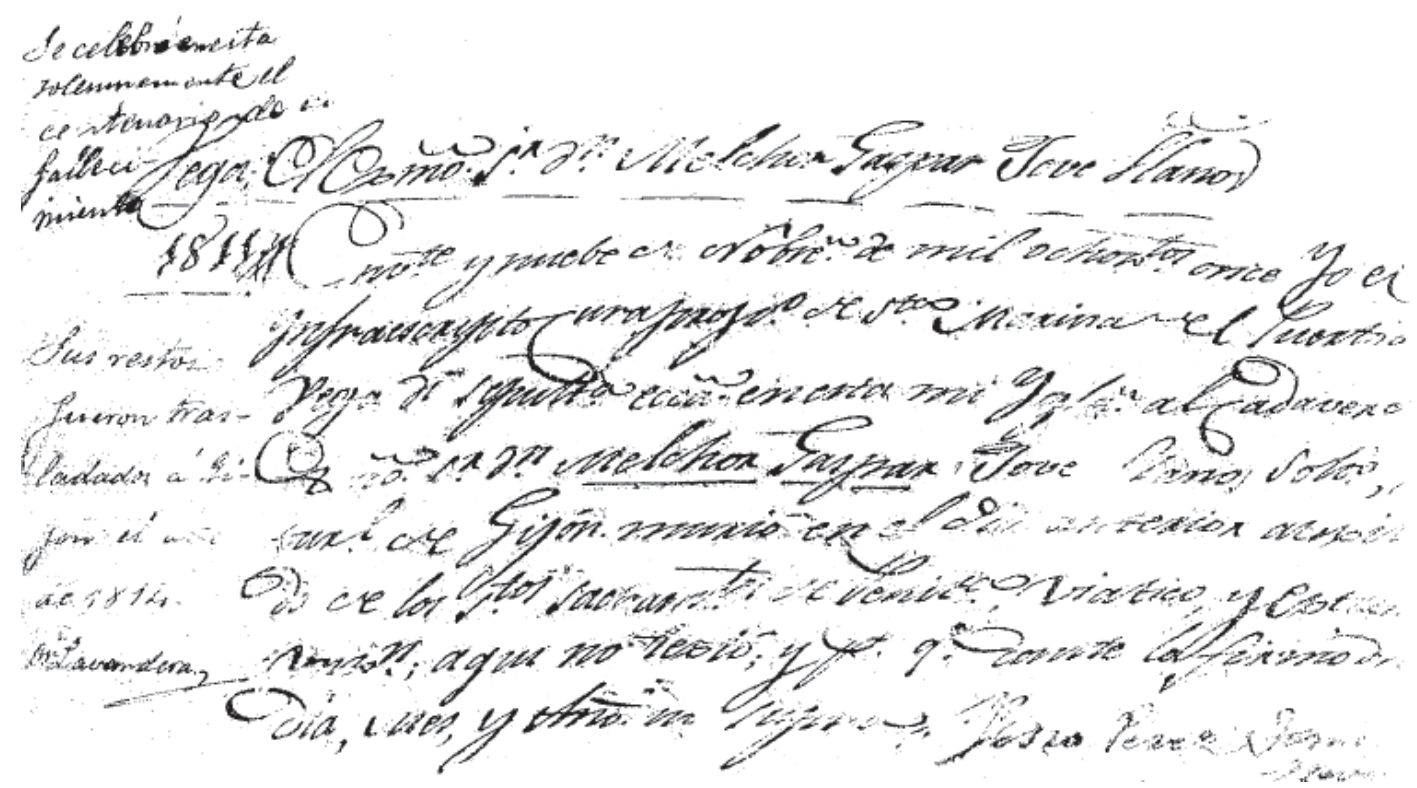

del sobrino y heredero del fallecido, Baltasar Cienfuegos-Jovellanos, quien se inclinaba decididamente por el día 27 en un documento donde ratificaba la posesión de la finca Les Figares a favor del fiel criado García de la Fuente, la cual le fue cedida en Isla de León el día 4 de febrero de 1810 por mano de Jovellanos, una vez posesionado el heredero del legado testamentario de su tío en el mes de enero de 1812.

También defendió como más plausible la fecha del 27 de noviembre el recientemente desaparecido Marino Busto. Sin embargo, esta tesis se contradice —y en ello fundamentaba tenazmente su argumento Jesús Martínez- con lo expresado en la mencionada acta de defunción, conservada celosamente en el Libro V de Defunciones de la parroquia de Santa Marina de Vega, la cual, al folio 65 vuelta, dice textualmente:

Vega. Excmo. Sr. Dn. Melchor Gaspar Jove Llanos.

1811. En veinte y nueve de noviembre de mil ochocientos once, yo, el infraescripto cura propio de Santa Marina del Puerto de Vega di sepultura eclesiástica en esta mi iglesia al cadáver del Excmo. Sr. Dn. Melchor Gaspar Jove Llanos, soltero, natural de Gijón; murió en el día anterior auxiliado de los santos sacramentos de la Penitencia, Viático y Extremaunción; aquí no testó y para que conste la firmo dicho día, mes y año ut supra. Pedro Pérez Tames Hevia.

Al margen, el párroco Benito Penzol Lavandera anotó una breve leyenda: «Sus restos fueron trasladados a Gijón en el año 1814. Se celebró en ésta solemnemente el centenario de su nacimiento. Firmado, Dr. Lavandera». 
El sepelio del prócer gijonés fue oficiado por su paisano y párroco local Pedro Pérez-Tamés y Hevia, acompañado de cuarenta sacerdotes de las feligresías del distrito y del provisor de la diócesis —el cual compareció revestido de capa pluvial—, siendo inhumado el cadáver a la una de la tarde del día mencionado y «en caja decente», según testimonia Ceán, mientras una compañía de soldados le rendía un respetuoso homenaje. Fueron testigos de tan luctuosa despedida —además de los que le habían acompañado en el azaroso viaje, como el cirujano Lamagna, Pedro Zuláibar y Eugenio García Sala—, algunos vocales de la Junta General y el oidor de la Real Audiencia ovetense, señor Acebedo, quienes se habían desplazado desde Castropol; asistió también la distinguida señora Josefa González Valdés de Rendueles, además de otros muchos de sus amigos, como los candasinos José Rodríguez Busto y Antonio de Condres, ambos relacionados con su Instituto gijonés y a la sazón también desplazados en Figueras (Castropol) cuando se conoció el dramático epílogo de la vida del insigne asturiano. El segundo era profesor de Náutica, Francés e Inglés en el Real Instituto; en cuanto a Rodríguez Busto, fue autor a posteriori de unos «Apuntes biográficos», donde anotó:

Hallándome en el año 1811 confinado en el puerto de Figueras [...] recibí la infausta noticia de que el Excmo. Sr. Dn. Melchor Gaspar de Jovellanos, emigrado también de Gijón, se encontraba gravemente enfermo y en el mayor peligro de su vida en el puerto de Vega [...]. La gratitud y acendrado amor que le profesaba me obligaron a correr y, a pie, con otro compañero, a visitarle, y ambos tuvimos la fatal desgracia de asistir y presenciar los últimos suspiros [...]. Toda aquella noche la pasamos a su lado y lo acompañamos hasta dejarlo sepultado en la citada villa de Vega, regresando llenos del más acerbo dolor por tan infausta pérdida.

Fue, pues, enterrado Jovellanos bajo el enlosado de la parroquial de Santa Marina de Puerto de Vega, enfrente del altar mayor, al pie de las gradas del presbiterio y en el lugar de la epístola, muy cerca del lugar donde descansaba el cuerpo de su fiel amigo Valdés Llanos, que bien pudo ocupar un puesto en la sepultura dotada por su suegro y en la que también debía de yacer su esposa ${ }^{17}$. Según refiere José Ramón de Luanco, quien visitó el lugar donde había estado depositado el cuerpo de Jovellanos en el año 1849, en compañía de Pedro Santamarina —aquel joven con quien Jovellanos departió supuestamente en el pórtico de la iglesia poco antes de enfermar-, el párroco se olvidó de registrar, como

17 La Fundación Cultural «Amigos de la Historia» colocó el 1 de mayo de 1996 una placa conmemorativa de bronce, en presencia de varios miembros del Foro Jovellanos y ante la contenida emoción popular, en el lugar exacto donde el profesor José Miguel Caso y el autor de estas páginas identificaron la ubicación exacta de la desaparecida tumba, el día 10 de agosto de 1993. 
era preceptivo, el día de la exhumación de los restos para su traslado a Gijón ${ }^{18}$. Aquel involuntario descuido del párroco fue subsanado por uno de sus sucesores en el magisterio pastoral, el doctor don Benito Penzol Lavandera, si bien varias décadas después ${ }^{19}$.

El traslado de los restos mortales a Gijón hubo de ejecutarse en el año 1815, si bien nos encontramos con un nuevo problema en la datación, pues se ha consolidado la fecha del año anterior, inducido por el testimonio colateral del párroco Penzol Lavandera y por el dato consignado por Fermín Canella en una biografía del fiel criado Domingo García de la Fuente ${ }^{20}$, aunque unas notas manuscritas del inseparable servidor del prócer ubica el evento, casi incuestionablemente, el día 25 de septiembre de 1815, celebrándose un oficio religioso ante el catafalco con los restos mortales del gijonés, exhumados el día anterior. Esta fecha es confirmada igualmente por José Miguel Caso en una notoria biografía, rectificando una noticia publicada por Jesús Martínez, aunque éste ya la había modificado en una comunicación fechada en el año $1970^{21}$.

En el diario del leal servidor García de la Fuente, éste dejó testimonio escrito de que habían salido de Gijón el jueves, 21 de septiembre, habiendo realizado la exhumación el domingo 24, a las cuatro de la tarde y celebrado un oficio de las ocho de la mañana del día 25, con cinco curas y el párroco; organista y cantor, etc. Pero hay un anotación contradictoria, capaz de suscitar de nuevo la confusión sobre la fecha del traslado, pues su interpretación textual nos lleva inexorablemente al año 1814. El párrafo susceptible de confusión dice así: «a quien cuidó dos años y medio poner, y encender y quitar las cuatro hachas sobre la sepultura (dan más los de la parroquia), 4. ${ }^{\circ}$ reales ${ }^{22}$. En cualquier caso, los restos mortales del desdichado polígrafo gijonés encontraron merecido descanso en la iglesia gijonesa de San Pedro en 1842 y, tras la destrucción de la misma en la contienda civil del año 1936, reposan definitivamente en la capilla de los Remedios.

Una de las obras más delicadas y entrañables del gijonés, los Diarios, llegaron a manos del erudito Alejandrino Menéndez de Luarca, propietario y residente

18 J.R. LuAnco, «Postrimerías y recuerdos», La Ilustración Gallega y Asturiana, t. 111 (3 de noviembre de 1881), pág. 336. Reproducido en el semanario La Comarca del Eo, Lugo (15 de agosto de 1992), por M. A. Serrano Monteavaro.

19 En la actualidad, aún es legible, si bien con cierta dificultad, un añadido en el Libro de Defunciones, obviamente manuscrito, que dice: «Se celebró en ésta solemnemente el centenario del fallecimiento (en) 1811. Sus restos fueron trasladados a Gijón el año de 1814».

20 F. Canella Secades, Domingo García de la Fuente, Oviedo, 1902, págs. 117-126.

21 J.M. Caso, Biografía de Jovellanos, Gijón, Foro Jovellanos, 1998, pág. 113; J. MarTínez Fernández, «El último viaje de Jovellanos», BIDEA, n. 58 (1966), pág. 36.

22 J. Martínez Fernández, Jovellanos: patobiografía y pensamiento biológico, Oviedo, IDEA, 1996, pág. 33 . 
en el palacio franquino de Fonfría; años después, su viuda, Joaquina Castrillón, los entregó para la impresión al Claustro de la Universidad ovetense, según una noticia reflejada en El Avance Asturiano. Un pequeño perrito, llamado «Tufo», permaneció en Vega — según versificó Acevedo Huelves en una sección poética del diario gijonés El Noroeste - al cuidado de la familia Trelles, la cual aún conserva el collar con tres cascabeles de plata, que habían sido antes de «Piccolín», el perrito que le acompañó en el destierro de Bellver, regalo del capitán de la guardia suiza del palacio mallorquín ${ }^{23}$.

En el año 1864, el solado de la iglesia parroquial fue transformado, suprimiéndose entonces las dotaciones de tumbas del interior de la iglesia; intuimos que en ese momento se debió perder la que había cubierto los restos mortales de Jovellanos, cuya poética leyenda inscrita la habría hecho hasta entonces merecedora de conservación por los celosos párrocos y por el mismo vecindario. Por fin, la alcoba donde se produjo el óbito se mantuvo inmaculada muchos años, hasta que el banquero y diputado Vicente Trelles González decidió el traslado de la florida cama salomónica a su nuevo y monumental domicilio de Luarca. Una reproducción fotográfica de la misma aparece en una conocida guía de Asturias ${ }^{24}$.

En la casa mortuoria se colocó una lápida, redactada por Juan Nicasio Gallego y Manuel José Quintana, por disposición de Acisclo Fernández Vallín, en el año 1892. Dice así:

En esta casa murió el Excmo. Sr. D. Gaspar Melchor de Jovellanos, Magistrado, Ministro, Padre de la Patria, no menos respetable por sus Virtudes que admirable por sus talentos; urbano, íntegro, celoso promovedor de la cultura y de todo el adelanto de su país; literato, orador político, jurisconsulto, filósofo, economista, que se dedicó a buscar el esplendor de España mientras vivió y es eterna gloria de su provincia y de su familia. Nació en Gijón el 5 de enero de 1744. Murió el 27 de noviembre de 1811.

El espíritu jovellanista permanece vivo en Puerto de Vega. Buen ejemplo de ello es la calle que lleva su nombre, la mencionada casa obituaria y el busto, inaugurado el día 4 de septiembre de 1932, ubicado entonces al lado de la capilla de la Atalaya, que consistía en un monolito de piedra pizarrosa, en cuyo ático se fijó la cabeza de Jovellanos. Posteriormente, se le trasladó a la entrada del campo de la Atalaya, siendo reinaugurado el 15 de enero de 1983. Así mismo, el día 28

23 A. GuZmán SANCho, «Nuevas postrimerías de Jovellanos», pág. 53.

24 Gijón, Ediciones Matéu, 1923, pág. 87. 
de noviembre de 1933 se había fundado la Biblioteca Popular Circulante, que respondía al nombre del ilustrado Jovellanos; en recuerdo de ello, se ha recuperado la misma denominación para la actual Biblioteca Pública Municipal, cuya sala principal se halla presidida por la imagen del prócer, donada por el Grupo Excursionista Gijonés a la desaparecida Sociedad Popular de Cultura y Recreo en la mencionada visita del día 4 de septiembre de 1932. 